\title{
Environmental impacts of imported and locally grown fruits for the French market: a cradle-to-farm-gate LCA study
}

\author{
Claudine Basset-Mens ${ }^{1, \star}$, Henri Vannière ${ }^{1}$, Dominique Grasselly ${ }^{2}$, Hadrien Heitz ${ }^{1,3}$, Angela Braun ${ }^{1}$, \\ Sandra Payen ${ }^{1,4}$, Peter Koch ${ }^{5,6}$ and Yannick Biard ${ }^{1}$ \\ 1 CIRAD, UR Hortsys, ELSA, TA B-103/C, Campus international de Baillarguet, 34398 Montpellier Cedex 5, France \\ 2 CTIFL, route de Molleges, F13210 Saint-Rémy-de-Provence, France \\ 3 ENVILYS, Domaine du Chapitre - 170 bd du Chapitre, 34750 Villeneuve-lès-Maguelone, France \\ 4 ADEME, 20 avenue du Grésillé, 49004 Angers, France \\ 5 Agroscope, Institut für Nachhaltigkeitswissenschaften INH, Reckenholzstrasse 191, 8046 Zürich, Switzerland \\ 6 Koch Consulting, Röschibachstrasse 77, 8037 Zürich, Switzerland
}

Received 22 June 2015 - Accepted 28 October 2015

\begin{abstract}
Introduction. Fruits are under growing scrutiny regarding their environmental impacts. However, fruit cropping systems have seldom been studied using life cycle assessment (LCA). As part of the Agribalyse ${ }^{\circledR}$ project, the cropping systems for apple and peach in France, clementine in Morocco, and mango in Brazil were evaluated with a cradle-to-farm-gate LCA in order to include the manufacturing, transportation and utilization of all inputs used on the farm. Materials and methods. Representative systems for each fruit were designed, relying mostly on expert knowledge for apple, peach and clementine, and on a detailed survey of eight commercial orchards for mango from the Rio San Francisco Valley in Brazil. Potential environmental impacts were calculated using the ReCiPe Midpoint (H) method. Results and discussion. For most impact categories, apple showed the least impacts, followed by mango, peach and clementine. For marine eutrophication, mango and small citrus had the least impact, followed by apple and peach far above. For ecotoxicity, mango had the least impact followed by apple, peach and clementine far above. For each fruit cropping system, margins of improvement were identified and associated with agronomic recommendations. Generally speaking, the key aspects driving the eco-efficiency of fruit cropping systems at the farm gate were the yield, the fertilizer rates, the use of toxic substances for pest management, the water requirement associated with its local availability and the energy source for irrigation. The ecotoxicity results revealed were uncertain due to the difficulty of determining representative crop protection practices for perennial crops. Conclusion. The Agribalyse ${ }^{\circledR}$ program represented an important step forward for the environmental assessment of fruits. Complementary research is needed to design better crop protection practices, field emissions and water-use impacts.
\end{abstract}

Keywords: Brazil / France / Morocco / apple (Malus domestica) / peach (Prunus persica) / mango (Mangifera indica) / clementine (Citrus clementina) / environmental impacts / life cycle assessment / hot-spots

Résumé - Impacts environnementaux des fruits importés ou cultivés localement pour le marché français : ACV du berceau à la porte de la ferme. Introduction. L'attention portée aux impacts environnementaux associés à la production fruitière est grandissante. Pourtant, les systèmes de culture fruitiers ont rarement été étudiés par l'analyse du cycle de vie (ACV). Dans le cadre du projet Agribalyse ${ }^{\circledR}$, les systèmes de production de pommes et de pêches en France, de clémentines au Maroc et de mangues au Brésil ont été évalués avec l'ACV du berceau à la porte de la ferme, afin de prendre en compte la fabrication, l'acheminement et l'utilisation de tous les intrants utilisés sur l'exploitation agricole. Matériel et méthodes. Un système représentatif pour chaque fruit a été conçu en se basant principalement sur les connaissances d'experts en pomme, pêche et clémentine et sur une enquête détaillée de huit vergers commerciaux de mangue dans la vallée du Rio San Francisco au Brésil. Les impacts environnementaux potentiels ont été calculés en utilisant la méthode ReCiPe $(\mathrm{H})$ Midpoint. Résultats et discussion. Pour la plupart des catégories d'impact, la production de pomme a montré des impacts moindres, suivie par la mangue, la pêche et la clémentine. Pour l'eutrophisation marine, la mangue et la clémentine ont eu le moins d'impact, suivies par la pomme et la pêche bien au-dessus. Pour l'écotoxicité, la mangue a eu le moins d'impact suivie par la pomme, la pêche et la clémentine bien au-dessus. Pour chaque système de culture fruitière, des marges d'amélioration ont été identifiées et associées à des recommandations

^ Corresponding author: claudine.basset-mens@cirad.fr 
agronomiques. De façon générale, les aspects-clés de conduite de l'éco-efficacité des systèmes de culture fruitière à la porte de la ferme étaient le rendement, le niveau de fertilisation, l'utilisation de substances chimiques pour la lutte antiparasitaire, les besoins en eau associés à sa disponibilité et la source d'énergie locale pour assurer l'irrigation. Les résultats d'écotoxicité sont les plus incertains en raison de la difficulté à déterminer des pratiques représentatives de protection des cultures pour les cultures pérennes. Conclusion. Le programme Agribalyse ${ }^{\circledR}$ a représenté une étape importante pour l'évaluation environnementale de la production fruitière. Des recherches complémentaires sont nécessaires pour mieux modéliser les pratiques de protection des cultures, les émissions aux champs et les impacts de l'utilisation de l'eau.

Mots clés : Brésil / France / Maroc / pomme (Malus domestica) / pêche (Prunus persica) / mangue (Mangifera indica) / clémentine (Citrus clementina) / impacts environnementaux / analyse du cycle de vie / points-critiques

\section{Introduction}

Like all other food products traded globally, fruits are under growing scrutiny regarding their environmental impacts [1]. Beyond the impacts due to the cumbersome logistics of fruit, the farm stage is generally of paramount importance in their total impacts in relation to the use of energy and water for irrigation, fertilizers and pesticides. In France, the Agribalyse ${ }^{\circledR}$ program was launched by the French environment agency (ADEME) in 2009 to support environmental labeling as planned by the "Grenelle de l'environnement" round tables, but also to contribute to the eco-design of farms and cropping systems through the identification of their environmental hot-spots. The life cycle assessment (LCA) methodology foresees the evaluation of all environmental impacts attached to a function, product or service over its complete life cycle. It is used to compare different technical alternatives fulfilling the same function and to identify the hot-spots of the studied systems. Its conceptual framework is described in two ISO norms [2,3] and consists of 4 steps: goal and scope definition, inventory, impact assessment and interpretation. Based on a cradle-to-farm-gate LCA in order to include the manufacturing, transportation and utilization of all inputs used on the farm, the objective of Agribalyse ${ }^{\circledR}$ was the development of a homogeneous and consensual Life Cycle Inventory (LCI) database for French agricultural products and a few imported products. The evaluation of fruit cropping systems with LCA is quite recent, the most studied fruits being citrus [4-8] and apple [9-11]. Ingwersen [12] recently published a full LCA study on pineapple from Costa Rica, but tropical fruits have seldom been studied with complete LCA studies. The application of LCA to fruit cropping systems has revealed specific challenges related mostly to their variable and perennial cropping systems, frequent pesticide treatments and use of irrigation water [10,13-15]. Although most LCA studies do not account for the perennial cycle of fruit cropping systems, certain authors have recommended the inclusion of all phases of fruit orchards in the LCA modeling of fruits including the nursery, orchard installation, growing of trees, full production phase and possibly the decreasing-yield phase and dismantling of the plantation [7, 13-15]. Bessou et al. [13] proposed a formalization of the different possibilities to account for perennial cropping systems depending on the objective of the study and data availability. The same authors also highlighted the inadequacy of the usual methods for estimating field emissions for perennial cropping systems, especially under tropical, subtropical or semi-arid conditions. Finally, several authors also raised the issue of the choice of functional unit and allocation procedures for comparing fruit products, insisting on the various qualities of fruit including their edible content $[12,15]$. In a context of recent application of LCA to the fruit sector, the objective of the Agribalyse ${ }^{\circledR}$ program was not to develop new research but to properly apply the consensual and up-to-date methodology for all agricultural products including fruits. In France, $50 \%$ of fruits are produced locally and 50\% are imported, often from distant and warm countries. Two locally produced fruits: apple (Malus domestica) and peach (Prunus persica), and two imported from overseas: clementine (Citrus clementina) from Morocco and mango (Mangifera indica) from Brazil were evaluated.

The objectives of this paper are:

- To present the methods and data used to design and assess fruit cropping systems in each situation.

- To present and discuss the cradle-to-farm-gate LCA results for apple, peach, clementine and mango in relation to the existing literature, methodological choices, data availability and studied functions.

- To identify the hot-spots and some margins of improvement for fruit cropping systems and research perspectives.

\section{Materials and methods}

\subsection{Goal and scope}

In line with the Agribalyse ${ }^{\circledR}$ method [16], the functional unit used was $1 \mathrm{~kg}$ raw fruit at the farm gate. Representative systems for each fruit were designed, relying mostly on expert knowledge for apple, peach and clementine, and on a detailed survey of eight commercial orchards for mango from the Rio San Francisco Valley in Brazil. The reference period defined in the Agribalyse ${ }^{\circledR}$ report is 5 years from 2005 to 2009 , but must extend to 10 years for strongly alternating productions such as fruits. This was formally possible for mango where data were collected over more than 20 years on real orchards, but relied on expert advice for other fruits supposed to include seasonal and regional variability over the orchard's life cycle. For crop protection practices, data were based on a large sample survey (349 field surveys) for apple, on expert advice for peach and clementine, and on average data for the 8 surveyed orchards for mango. For all fruits, the full orchard life cycle was modeled according to recent practice as presented in Section 2.2.1 using either real data or expert advice. 


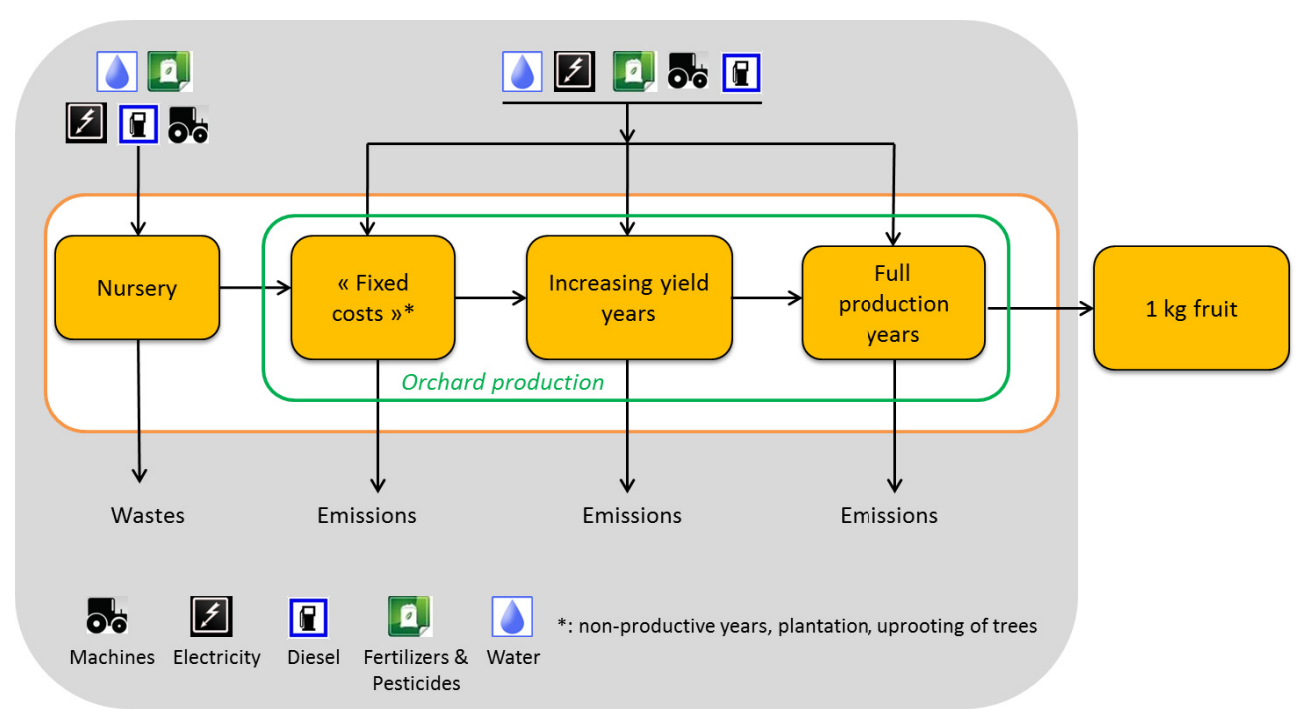

Figure 1. Cradle-to-farm-gate fruit systems for apple and peach in France, mango in Brazil and clementine in Morocco.

\subsection{Systems studied}

In agreement with the Agribalyse ${ }^{\circledR}$ method, the system boundaries were set from cradle-to-farm-gate including the production, transport and use on the farm of all inputs except very minor tools and inputs, e.g. pruners, and non-agricultural buildings (figure 1). For the contribution analyses of our systems presented in Section 3, processes will be grouped under three main groups:

- Group 1: Fertigation (fertilizers in the irrigation water), further subdivided into four sub-groups (i) electricity consumption; (ii) fertilizer manufacturing and transportation; (iii) field emissions due to fertilizer application and (iv) other minor fertigation-related processes.

- Group 2: Crop protection, including in one single box manufacturing and transportation of pesticides, field application and field emissions due to application of pesticides.

- Group 3: Other operations (such as soil preparation, plantation, tree maintenance, harvesting, etc.).

\subsubsection{Modeling of perennial cropping systems}

According to the Agribalyse ${ }^{\circledR}$ methodology, the perennial cropping system was initially modeled in four phases: nursery (or plant production), fixed costs (including plantation, nonproductive years and uprooting of trees at the end of the orchard's life), increasing yield years and full production years. This implied collecting or estimating representative data for all four phases in terms of agronomic practices and duration. An important assumption for perennial cropping systems is the lifetime of the orchard. It was assumed to be 20 years for apple, 15 years for peach, and 25 years for mango and clementine.

\subsubsection{Apple from France}

Apple is mainly produced in the South-East, the SouthWest and the Loire Valley regions in France, with 38\%, 31\% and $23 \%$ surface-wise, respectively [17]. In each region, experts on apple production from technical extension services and farmers' associations participated in the design of most representative apple production systems for the recent period. The average conventional system was a combination of nonscab and scab-resistant (or tolerant) varieties across all regions weighted by their respective share. Crop protection practices were based on a survey from a large sample of orchards (about 100 field surveys over three seasons for the period 20062008). These data for the full production phase (years 5 to 20) were extrapolated to the entire life cycle of the orchard, ignoring the constant evolution of active substances certification. Since pesticide applications are a function of the tree size and foliage volume in practice, for the first (non-productive) years, crop protection practices were assumed to be one-third of those for full production years, while they were assumed to be two-thirds for increasing yield years (from 2 to 4 ). Only the most common substances were selected from the survey. Data for the nursery phase was based on the survey of two nurseries, one in the Loire Valley region and the other in the South-East region. Key agronomic data for the full production phase of apple production and other fruits are presented in table $I$.

\subsubsection{Peach from France}

The production of peach is mainly located in the South of France. Similarly to the apple inventory, experts on peach production from technical extension services and farmers' associations were involved in the design of the most representative peach production systems for France for the recent period. Based on national statistics from Agreste [17], the national average system was the weighted (surface-wise) combination of early, median and late productions, influencing the yield, mechanization requirements, crop protection and irrigation practices (see table $I$ for the average full production phase). Two commercial nurseries representing more than $25 \%$ of the production of peach grafted plants were surveyed to design the nursery phase. Crop protection practices were based 
Table I. Main agronomic data for the full production phase of apple, peach, mango and clementine. Values are given per annum.

\begin{tabular}{llcccc}
\hline Intervention & Unit & Apple & Peach & Mango & Clementine \\
\hline Country of reference & & France & France & Brazil & Morocco \\
Orchard age & years & 20 & 15 & 25 & 25 \\
Density & trees ha $^{-1}$ & 1,730 & 640 & 280 & 500 \\
Yield & $\mathrm{t} \mathrm{ha}^{-1}$ & 53.7 & 28.0 & 33.0 & 28.0 \\
\hline Fertilization & & & & & \\
$\mathrm{N}$ & $\mathrm{kg} \mathrm{ha}^{-1}$ & 50 & 110 & 165 & 180 \\
$\mathrm{P}_{2} \mathrm{O}_{5}$ & $\mathrm{~kg} \mathrm{ha}^{-1}$ & 30 & 100 & 100 & 45 \\
$\mathrm{~K}_{2} \mathrm{O}$ & $\mathrm{kg} \mathrm{ha}^{-1}$ & 125 & 220 & 273 & 180 \\
\hline Irrigation & & & & & \\
Water & $\mathrm{m}^{3} \mathrm{ha}^{-1}$ & 2,767 & 7,000 & 7,999 & 8,000 \\
Energy & $\mathrm{MJ} \mathrm{ha}^{-1}$ & 2,988 & 7,560 & 2,946 & 22,830 \\
\hline Plant protection products & & & & & \\
Total herbicides & $\mathrm{kg} \mathrm{ha}^{-1}$ & 3.40 & 4.40 & 0.00 & 10.20 \\
Total insecticides & $\mathrm{kg} \mathrm{ha}^{-1}$ & 5.10 & 0.70 & 0.30 & 9.58 \\
Total fungicides & $\mathrm{kg} \mathrm{ha}^{-1}$ & 38.40 & 24.20 & 5.66 & 16.50 \\
\hline Total pesticides & $\mathrm{kg} \mathrm{ha}^{-1}$ & 46.90 & 29.30 & 5.96 & 36.28 \\
Growth regulators & $\mathrm{kg} \mathrm{ha}^{-1}$ & 0.20 & 0.00 & 4.03 & 0.02 \\
Petroleum oils & $\mathrm{kg} \mathrm{ha}^{-1}$ & 12.3 & 16.3 & 0.0 & 0.0 \\
\hline
\end{tabular}

on expert knowledge for the full production phase (years 5 to $15)$ and extrapolated to other phases of the orchard. Since pesticide applications are a function of the tree size and foliage volume in practice, it was assumed that one-third of pesticide inputs from the full production was applied for the first nonproductive years (years 1 and 2) and two-thirds for increasing yield years (years 3 and 4 ).

\subsubsection{Mango from Brazil}

Brazil is the leading supplier of fresh mangoes to the EU. In the Rio San Francisco Valley, which concentrates more than $90 \%$ of the Brazilian mango exports, modern and intensive production systems have developed. These systems feature year-round production thanks to well-controlled floral induction and abundant dam water access. In this region, a sample of eight contrasted 'Kent' and 'Tommy Atkins' mango orchards was surveyed in 2012. Data over the complete crop cycle of mango trees was collected, over more than 20 years for older orchards. Despite this detailed and very time-consuming survey, many input data were missing. Only the yield was consistently available across the whole of the orchard cycle and the 8 orchards. Annual averages for all input and yield data available across the eight orchards were first calculated and then aggregated into average data for each phase (see table I for the full production phase). Since the oldest orchard was only 21 years old and the assumed lifetime of the mango orchard was 25, all input and yield data for the last four years were extrapolated from the average of each input and yield data for the full production phase. No nursery was included since grafted plants are produced on-farm.

\subsubsection{Clementine from Morocco}

In Morocco, clementines for export to France are produced in two main regions of production: the Souss region and the Oriental region (Berkane area) with, for the 20092010 season, $55.6 \%$ and $32.8 \%$ of clementines exported, respectively [18]. Until recently in each region, specific varieties and cropping system management were used. In the Oriental region, traditional practices included mainly clementine varieties such as 'Cadoux', low-density orchards (270 trees ha $\left.{ }^{-1}\right)$ and gravity irrigation, while in the Souss region the management was more modern and intensive, using mostly the 'Nour' variety, high-density orchards (500 trees $\mathrm{ha}^{-1}$ ) and drip irrigation. According to local experts, the Oriental system is rapidly evolving toward a more modern management very similar to the Souss system. For this reason, the Souss system using the 'Nour' variety, high-density orchards and drip irrigation was chosen as the most representative for the Moroccan clementine for export to France. Key input and yield data for the representative Souss-'Nour' system were based on expert knowledge of the clementine production in Morocco for each phase of the citrus orchard (see table I for the full production phase). Other more specific operations and data were based on a detailed survey over the whole orchard life cycle of one commercial orchard of clementine from the Beni Mellal region. Regarding crop protection practices, the main pests were inventoried and the most common practices and active substances used for each pest defined. Other practices may exist. A detailed survey was conducted in a commercial nursery to design the nursery phase.

\subsection{Environmental inventory}

\subsubsection{Emissions from orchards}

To estimate field emissions, the Agribalyse ${ }^{\circledR}$ recommendations were applied [16]. Phosphate and pesticide emissions were calculated according to Nemecek and Kägi [19], assuming that $100 \%$ of the pesticides applied would be emitted to the soil. Nitrous oxide, carbon dioxide from urea and lime, and nitrate leaching were estimated according to the IPCC [20]. 
Table II. Cradle-to-farm-gate life cycle assessment (LCA) results per kg of raw fruit for a selection of environmental indicators (ReCiPe Midpoint (H); Cumulative Energy Demand) for apple, mango, peach and clementine.

\begin{tabular}{|c|c|c|c|c|}
\hline & Apple & Mango & Peach & Clementine \\
\hline Country of reference & France & Brazil & France & Morocco \\
\hline Climate change $\left(\mathrm{kg} \mathrm{CO}_{2}\right.$-eq) & 0.0678 & 0.139 & 0.170 & 0.269 \\
\hline 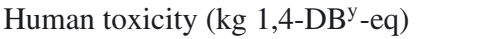 & 0.0273 & 0.0436 & 0.0664 & 0.0783 \\
\hline Terrestrial acidification ( $\mathrm{g} \mathrm{SO}_{2}$-eq) & 0.610 & 2.05 & 2.36 & 2.27 \\
\hline Freshwater eutrophication (g P-eq) & 0.0283 & 0.0715 & 0.0602 & 0.127 \\
\hline Marine eutrophication (g N-eq) & 0.233 & 0.0842 & 1.83 & 0.116 \\
\hline Terrestrial ecotoxicity (kg 1,4-DB-eq) & 0.00177 & 0.000230 & 0.00312 & 0.00699 \\
\hline Freshwater ecotoxicity (kg 1,4-DB-eq) & 0.00151 & 0.00071 & 0.00359 & 0.00616 \\
\hline Non-renewable energy $(\mathrm{MJ})$ & 1.12 & 1.46 & 2.54 & 3.32 \\
\hline
\end{tabular}

y 1,4-DB: 1,4-dichlorobenzene-eq for equivalent.

Ammonia emissions were based on emission factors from EMEP/CORINAIR [21] and nitrogen oxides according to EMEP/EEA [22]. According to IPCC [20], nitrate leaching was considered nil for mango and clementine because localized irrigation is used and rainfall is reduced in both regions (the daily irrigation (or rainfall) volume was constantly below the soil field capacity), while for apple and peach it was assumed to be $30 \%$ of the nitrogen inputs. The SALCA-SM method was used for trace elements but only for French products since data was missing for imported fruit [23, 24].

\subsubsection{Indirect inventory data}

Indirect inventory data were based on the Ecoinvent Life Cycle Inventories (LCI) database (version 2.2) available in the SIMAPRO software (version 7.3) and on processes developed specifically for the production systems studied and the country.

\subsection{Characterization of environmental impacts}

The impact assessment was performed using the ReCiPe Midpoint life cycle impact assessment method [25], adopting the Hierarchist perspective. The following environmental impact categories were considered: climate change (100 years; in $\mathrm{kg} \mathrm{CO}$-eq), terrestrial acidification (in $\mathrm{g} \mathrm{SO}_{2}$-eq), freshwater and marine eutrophication (in $\mathrm{g} \mathrm{P}$-eq and $\mathrm{g} \mathrm{N}$-eq, respectively, based on the nutrient-limiting factor of the aquatic environment), human toxicity (in g 1,4-DB-eq: 1,4-dichlorobenzene), and terrestrial and freshwater ecotoxicity (in g 1,4-DB-eq). The non-renewable energy consumption (fossil and nuclear; MJ-eq) was assessed using the Cumulative Energy Demand method [26]. To facilitate comparison with published LCA studies, life cycle impact assessment (LCIA) results using the CML 2001 methodology [27] were also calculated (see Sect. 2.5).

\subsection{Data quality assessment}

As part of the Agribalyse ${ }^{\circledR}$ methodology several data quality assessment procedures and an external critical review were implemented to evaluate the datasets [16]. For instance, the data quality of each dataset was assessed globally based on recommendations from the ILCD handbook [28]. This data quality assessment is based on six data quality indicators, namely: technological representativeness (TeR), geographical representativeness (GeR), time-related representativeness (TrR), completeness (C), precision and uncertainty (P), and methodological appropriateness and consistency $(\mathrm{M})$. For each indicator a score between 1 and 5, 1 being the best score and 5 the worst, is given independently. Then, the overall quality of the dataset can be derived from the quality rating of the various quality indicators based on equation (1):

$$
D Q R=\frac{T e R+G e R+T r R+C+P+M+X_{w} \times 4}{i+4}
$$

with $X_{w}$ the weakest quality level obtained among the data quality indicators and $i$ the number of indicators scored.

\subsection{Comparison with published LCA studies}

The cradle-to-farm-gate LCA results were compared with cradle-to-farm-gate LCA results from 9 published studies on fruits using the CML 2001 methodology [27] (table II). Incomplete LCA studies were discarded. Among all studies, climate change and non-renewable energy demand were the most consistently evaluated and could be systematically reported. Apart from Pergola et al. [7], who evaluated both non-renewable and renewable energy sources based on Lo Giudice et al. [29], all other authors used different versions of the Ecoinvent method for cumulative energy demand in MJ $[26,30]$. For eutrophication and acidification potentials, most studies used CML 2001 or EDIP97, which are identical for eutrophication and slightly different for acidification [31]. Several studies did not include toxicity impacts due to methodological limitations [5-7]. In other studies a range of approaches was used for toxicity impacts. Only results from studies using the CML methodology were selected $[4,11]$.

\section{Results and discussion}

\subsection{Compared cradle-to-farm-gate LCA results for apple, peach, mango and clementine}

Except for marine eutrophication, terrestrial ecotoxicity and freshwater ecotoxicity, apple generally revealed the least 


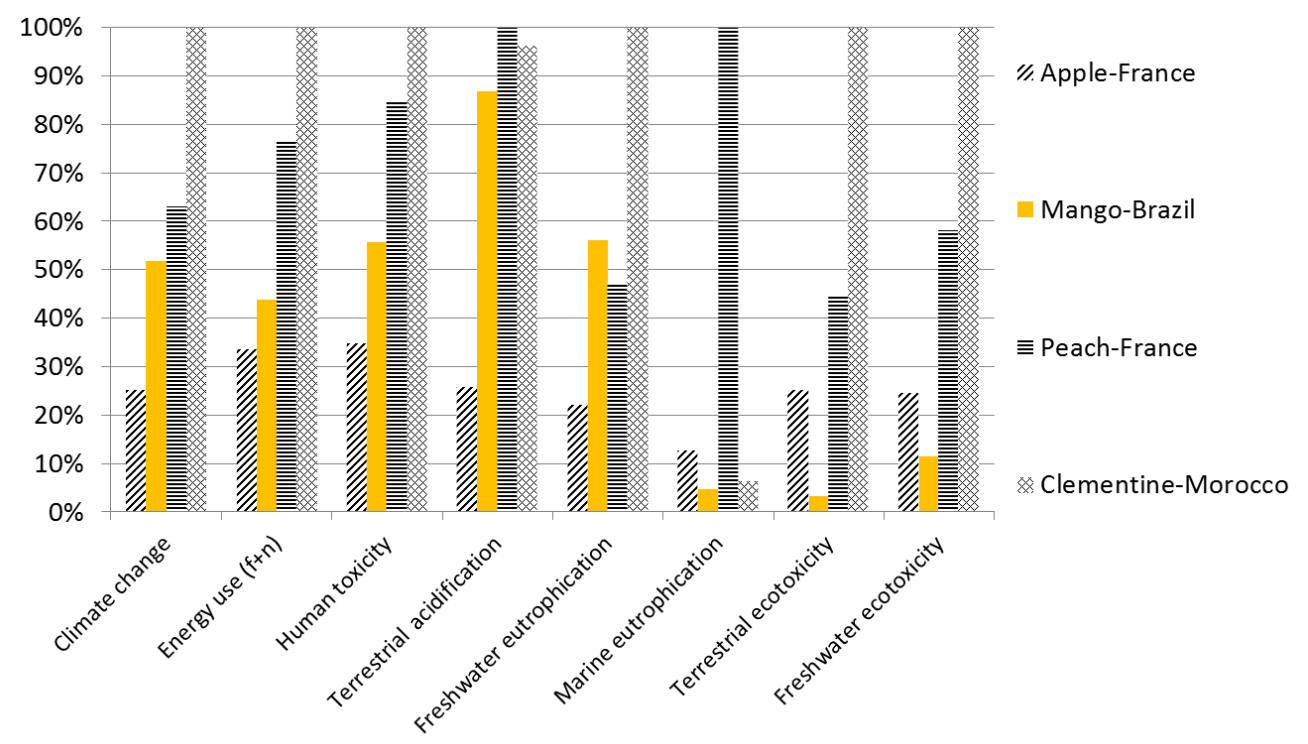

Figure 2. Cradle-to-farm-gate life cycle assessment (LCA) results per $\mathrm{kg}$ of raw fruit for a selection of environmental indicators (ReCiPe Midpoint $(\mathrm{H})$ ) for apple, mango, peach and clementine. Results are expressed as a percentage of the greatest result for each impact category.

impact per kg raw fruit at the farm gate, followed by mango, peach and clementine showing the greatest impacts (from twice to four times the apple impacts) (figure 2, table II). For terrestrial acidification, peach had the greatest impact, closely followed by clementine. For freshwater eutrophication, peach was ranked second instead of mango. These rankings were firstly due to the yield of raw fruits, ranging from $54 \mathrm{tha}^{-1}$ at full production for apple, to $33 \mathrm{t} \mathrm{ha}^{-1}$ for mango and $28 \mathrm{t}$ $\mathrm{ha}^{-1}$ for peach and clementine. A second important aspect was the fertilizer rates in orchards, increasing from apple to peach, mango and clementine. Overall, the two imported fruits showed higher fertilizer rates than the French ones. Another key reason for this ranking was the water availability in each context, the most favorable one being the mango situation, where water is freely available at the orchard entry gate thanks to the huge dam in this region, and the worst situation was that of clementine production, where water is scarce and has to be pumped deep in the groundwater. Finally, the energy used for pumping the water and the share of fossil energy in the electricity mix in each country also played an important role in the final impacts of the electricity consumption. It increased from France (less than 10\%) and Brazil (10\%) to Morocco (50\%).

Mango and clementine both had lower marine eutrophication (around $0.1 \mathrm{~g} \mathrm{~N}$-equivalent), compared with apple (above 0.2 ) and peach (1.8) (figure 2, table 2). This was explained by the use of IPCC nitrate emission factors: being nil under drip-irrigated crops in a semi-arid climate such as mango from Brazil and clementine from Morocco, but reaching 30\% of nitrogen inputs for crops under a temperate climate such as apple and peach from France. This method of estimation for nitrate leaching would warrant some improvement since the grassing of apple and peach orchards could not be accounted for by this approach.

Regarding terrestrial and freshwater ecotoxicity, mango showed the least impacts, followed by apple and then by peach, and finally by clementine far above (figure 2 , table II). The great ecotoxicity impact for clementine was essentially due to the use of chlorpyrifos-ethyl for controlling California red scale in clementine orchards in Morocco. This will be further developed in Section 3.6. The low ecotoxicity impact for mango can be explained by the highly favorable conditions of production for mango trees in the Rio San Francisco Valley in Brazil, and will also be further developed in Section 3.5.

\subsection{Comparison with published references}

No complete LCA studies for peach and mango could be found. For apple and clementine, our results were in the same range as results from the literature for climate change, nonrenewable energy use, eutrophication and acidification ( $t a-$ ble III). For toxicity impacts, only one reference for each product was found for comparison. Overall, results were of the same order and the literature references confirmed the least impacts of apple compared with citrus at the farm gate. This can be explained by higher nitrogen inputs and energy use for irrigation in citrus production associated with lower yields compared with apple.

\subsection{Hot-spot identification and margins of improvement}

For the four fruits, the contribution analyses are compared in relative terms for each impact category in figures $3 a-3 g$. Only the contribution analysis for terrestrial ecotoxicity is not presented, but still commented on in the text below.

\subsubsection{Apple}

Overall, the production of apple in France is efficient. For instance, the ratio $\mathrm{kg} \mathrm{N} \mathrm{kg}^{-1}$ apple produced is 0.93 . 


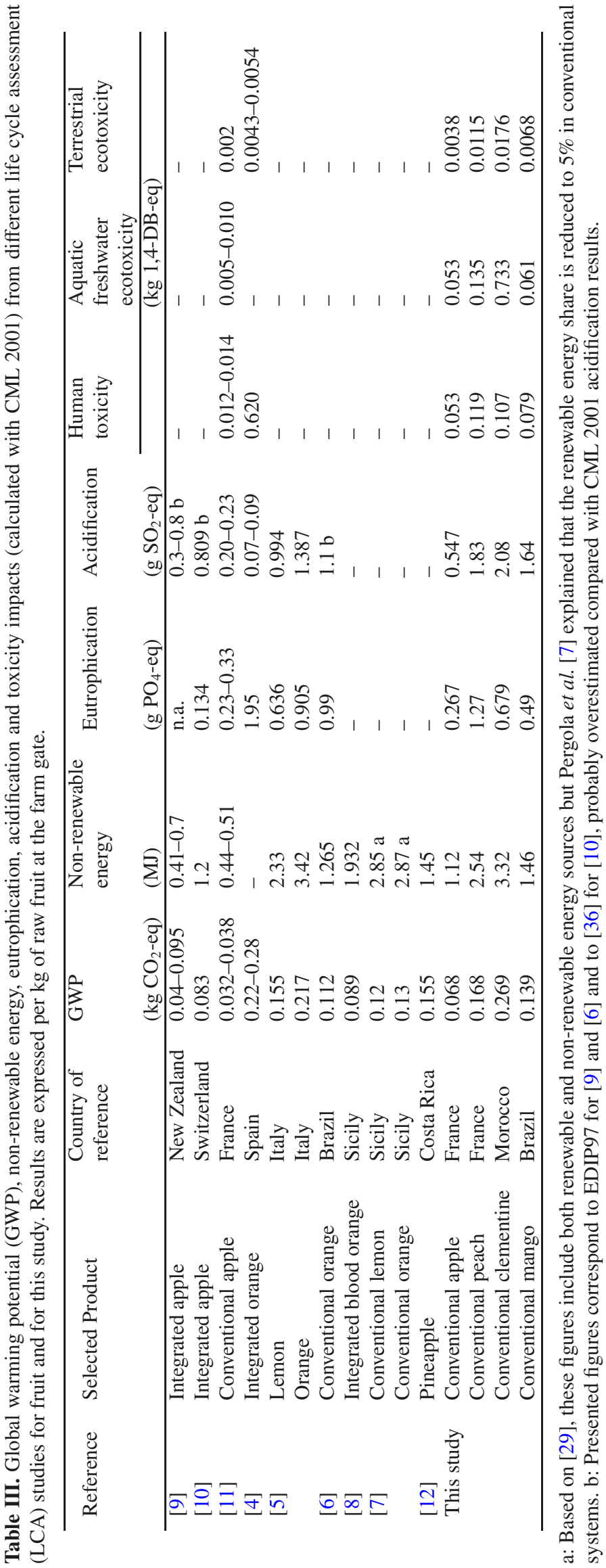



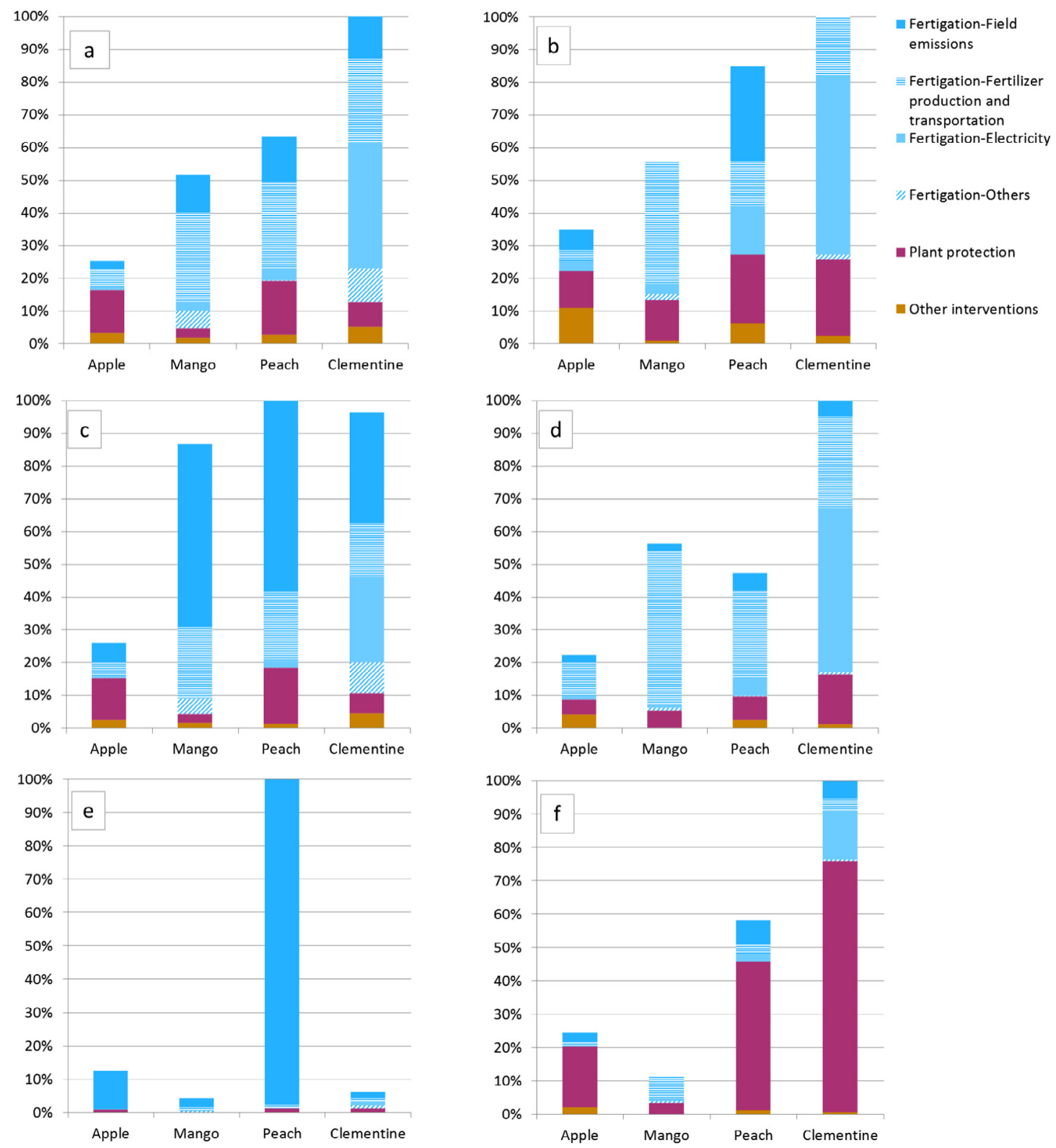

Figure 3. Contribution analysis for apple, mango, peach and clementine for climate change (a), human toxicity (b), terrestrial acidification (c), freshwater eutrophication (d), marine eutrophication (e), freshwater ecotoxicity (f), (ReCiPe Midpoint (H)) and non-renewable energy use (g) (CED). Results are expressed as a percentage of the greatest result for each impact category.

The water requirement is reduced. For most impact categories (climate change, human toxicity, terrestrial acidification, terrestrial ecotoxicity, freshwater ecotoxicity and non-renewable energy use) the main contributor for apple was the crop protection group, with impacts ranging from 33\% for human toxicity to $99 \%$ for terrestrial ecotoxicity. However, within the crop protection group, the more specific contributors depended on the impact category. For climate change, human toxicity, terrestrial acidification and non-renewable energy use, the mechanized application of pesticides was responsible for most of the crop protection group contribution due to numerous pesticide treatments over the season, while for terrestrial and freshwater ecotoxicity, field emissions of pesticides were responsible for most of the impacts for this group. The first five substances contributing to terrestrial ecotoxicity were in decreasing order: thiram (37.5\%), dithianon, dodine, chlorpyrifos and kresoximmethyl. For freshwater ecotoxicity, the main substances were thiram again $(36.0 \%)$, phosphorus, dithianon and nickel. For human toxicity, the other operations group also showed a significant contribution, with $31 \%$ of the total impact due to the use of self-propelled platforms on which farmers can stand for a long time to take care of trees. Overall, it was observed that in apple orchards mechanized operations for applying crop protection products or for other operations represented a very large share of most impacts through the use and combustion of diesel. For freshwater eutrophication, the main contributor was 
the manufacturing and transportation of fertilizers (45.0\%), followed by the crop protection group (21.0\%), while field emissions due to fertilizers only had a modest contribution $(11.3 \%)$. For marine eutrophication, field emissions due to fertilizers, and especially nitrate leached, contributed most at almost $89 \%$ of the total impact. Finally, it is noteworthy that electricity for irrigation represented almost $20 \%$ of all nonrenewable energy use but less than $3 \%$ of climate change due to the large share of nuclear electricity in the French electricity mix.

Several innovations are being studied to help reduce the consumption of diesel and the number of pesticide treatments in apple orchards. The first one consists of covering orchards with polyethylene plastic covers, which reduces the apple scab infestation to zero. Another system called Alcarpo ${ }^{\circledR}$ corresponds to the coverage of orchards with an insect-proof net, which allows reducing codling moth infestation to zero as well. Finally, localized and fixed systems for treating the trees against diseases and pests are also under study which could potentially drastically reduce the number of mechanized treatments and the diesel consumption.

\subsubsection{Peach}

The production of peach in France is intrinsically less efficient than apple. The fertilizer inputs are high. The ratio $\mathrm{kg} \mathrm{N} \mathrm{kg}^{-1}$ peach is almost 4.00 . The water requirement and related energy use are quite high. Pesticide treatments such as fungicides are also numerous but other mechanized interventions are less than in apple orchards, where the trellising of trees allows for easier and more diverse mechanized interventions.

For climate change and freshwater eutrophication, the manufacturing and transportation of fertilizers was the main contributor at $42 \%$ and $56 \%$, respectively. For freshwater eutrophication corresponding to P-limited eutrophication, the impact was related to the manufacturing of phosphorous fertilizers. For climate change, this included the impacts due to the production of compost applied in large amounts before the plantation. For both impact categories the second most important contributor was the crop protection group. For climate change, field emissions due to fertilizers (nitrous oxide emissions) also had a significant share at $22 \%$ of the total impact. For human toxicity, terrestrial acidification and marine eutrophication, field emissions due to fertilizers were the most impacting, with contributions of 34\% for human toxicity, 59\% for terrestrial acidification and $97 \%$ for marine eutrophication. The substances involved were for human toxicity: heavy metals, especially from fungicides, for terrestrial acidification: ammonia and NOx emissions, and for marine eutrophication: predominantly nitrate leached (at 95\%). For terrestrial ecotoxicity and freshwater ecotoxicity, the crop protection group constituted the predominant contributor, at more than $97 \%$ for terrestrial ecotoxicity and almost $77 \%$ for freshwater ecotoxicity. From this group, the impact was due to field emissions of pesticides, with the main contributing substances being thi$\operatorname{ram}(85 \%$ and $60.5 \%$, respectively), phosphorus for freshwater ecotoxicity and kresoxim-methyl for both at $11 \%$ and $7 \%$, respectively. Finally, electricity for irrigation contributed $20 \%$ to the use of non-renewable energy but similarly to the results for apple, its contribution to climate change was much less at 5\%, due to the small share of fossil energy in the French electricity mix.

The peach orchard age is quite short, which is not favorable to significant investments such as plastic covers or insect-proof nets as for apple orchards. Innovations currently focus on the reduction of pesticide treatments to manage pests and diseases such as mulching of the ground to reduce herbicide use, optimized spraying techniques or biological control, for instance through releases of beneficial insects. Regarding the reduction of the mineral fertilizer inputs, research should perhaps study the possible recycling of organic fertilizers and the breeding of more productive peach cultivars.

\subsubsection{Mango}

Mango from the Rio San Francisco Valley in Brazil benefits from favorable conditions of production in terms of environment and agronomic practices. Mango orchards have unlimited access to water at low energy cost while benefiting from dry and warm weather. In this context, farmers have developed year-round production thanks to well-controlled floral induction. Moreover, in Brazil, the most common pests for mango such as fruit flies are not as problematic as in Africa. This can be partly explained by the releases of infertile insect males by planes. Furthermore, the arid climate is not favorable to diseases such as powdery mildew and anthracnose, leading to reduced anti-fungal treatments. However, the ratio $\mathrm{kg} \mathrm{N} \mathrm{kg}^{-1}$ mango remains high at 5.00 despite the expertise of farmers.

For climate change, human toxicity, freshwater eutrophication, freshwater ecotoxicity and energy consumption, the main contributor was the manufacturing and transportation of fertilizers (from 52\% for climate change up to $83 \%$ for freshwater eutrophication).

For human toxicity, freshwater eutrophication and freshwater ecotoxicity, the second most important contributor was the crop protection group, with contributions of $22 \%, 9 \%$ and $28 \%$, respectively. For climate change, the second most important contributor was field emissions due to fertilizer application at $23 \%$, and this was due to nitrous oxide emissions. For terrestrial acidification and marine eutrophication, field emissions after application of fertilizers constituted the main contributor at $65 \%$ and $62 \%$ of the total impact, respectively. Ammonia volatilization was the main field emission responsible for these impact categories. For terrestrial acidification and marine eutrophication, the manufacturing and transportation of fertilizers was the second most important contributor at $25 \%$ and $20 \%$, respectively. For terrestrial ecotoxicity, the crop protection group was the main contributor, representing $80 \%$ of the total impact. The impact was mostly due to field emissions of pesticides with contributions from a wide range of substances, the most significant being ethephon, chlorothalonil, methomyl and dimethoate. No obvious hot-spots could be diagnosed for mango in terms of toxic pesticide use. Finally, electricity consumption for fertigation had small contributions to all impacts: from $0 \%$ to less than $6 \%$. 
Reducing the use of fertilizers per $\mathrm{kg}$ fruit therefore represents the best perspective of impact reduction for the mango production.

\subsubsection{Clementine}

For climate change, human toxicity, freshwater eutrophication and non-renewable energy consumption, electricity consumption for irrigation was the main contributor (from $39 \%$ for climate change to $55 \%$ for human toxicity). For terrestrial acidification and marine eutrophication, electricity showed the second greatest contribution at $27 \%$ and $23 \%$, respectively, with significant contributions from sulfur dioxide and nitrous oxides (figures $3 c$ and $3 e$ ). The large contribution of electricity to many impacts can be explained by two key factors: first, clementine requires a significant amount of water to grow but water is scarce in Morocco and water has to be withdrawn from more than 100 meter-deep wells. Second, fossil and electric pumps are used to pump this water in the ground water. Fossil pumps have significant climate change, acidification and non-renewable energy impacts, while electric pumps use the Moroccan electricity mix which is more than $50 \%$ based on fossil energy, which shows the highest impacts of all electricity sources. The Moroccan government and the producers are fully aware of this water and energy problem. As part of a national program called "Plan Maroc Vert", the government in collaboration with producers is seeking alternatives for consuming less water, having easier access to water or producing in regions where water is more easily accessible. Ambitious projects are being studied such as the building of new dams, rainfall storage or even a "water highway" from the North to the South of Morocco. A large power station based on renewable energy such as sun and wind is also being built and should hopefully allow the Moroccan electricity mix to include $40 \%$ renewable energy in a few years [32]. All these options will help reduce all the environmental impacts for citrus production.

Except for human toxicity, the second most important contributor for these impact categories was the manufacturing and transportation of fertilizers, ranging from $18 \%$ to $28 \%$. For terrestrial acidification and marine eutrophication, field emissions due to fertilizer application represented the main contributor at, respectively, 35\% and 29\% (figures $3 c$ and $3 e$ ). Moreover, among field emissions, ammonia volatilization constituted the main mechanism responsible for terrestrial acidification and marine eutrophication. The ratio $\mathrm{kg} \mathrm{N}$ per $\mathrm{kg}$ fruit is the highest of all fruits studied here at more than $6.00 \mathrm{~kg} \mathrm{~N} \mathrm{~kg}^{-1}$ clementine. To reduce impacts due to fertilizer use, planting more productive cultivars of clementine such as mandarin is an option. Research on the mineral nutrition of citrus could also help optimize the use of fertilizers.

For human toxicity, the crop protection group constituted the second major contributor at $23 \%$ (figure $3 b$ ). For terrestrial and freshwater ecotoxicity impacts, the pesticide use was the main contributor, at $99.7 \%$ for terrestrial ecotoxicity and $75 \%$ for freshwater ecotoxicity (figure $3 f$ ). For terrestrial ecotoxicity, field emissions of chlorpyrifos-ethyl contributed $63 \%$, while field emissions of methomyl contributed $35 \%$. For freshwater ecotoxicity, field emissions of chlorpyrifos-ethyl contributed $40 \%$, field emissions of methomyl 19\%, phosphorus $17.5 \%$ and nickel $11 \%$. Chlorpyrifos-ethyl is used for controlling California red scale in clementine orchards in Morocco. This molecule has a high toxicity potential and did not have an efficient alternative until recently. New substances such as spirotetramat have been tested in clementine orchards for a couple of years but this substance does not have a characterization factor yet in LCA models and therefore could not be tested in our study. Methomyl is another important insecticide for clementine used for controlling citrus leaf miners, especially for young trees. Research should be encouraged on this topic to help farmers identify less impacting practices for pest management.

Finally, another crucial hot-spot for this production which could not be reported in the Agribalyse ${ }^{\circledR}$ project is most probably water deprivation, as demonstrated for tomato production for export from the same region [33].

For further analysis of the contribution of the different orchard phases to the total LCA results of perennials including the nursery, plantation, non-productive years, increasing yield years and full production years, in Bessou et al. [34], the clementine case study is compared with an oil palm case study, with general discussion and recommendations.

\subsection{LCA comparison of fruits with the Agribalyse ${ }^{\circledR}$ methodology}

Until recently, fruits consumed in France had never been assessed with the LCA methodology. LCA references were therefore crucially needed to feed the eco-labeling program and debate on food products. Two locally grown and two imported fruits were evaluated with the LCA methodology following a consensual method like dozens of other French agricultural products. This constituted an important step forward. At the farm gate these studies confirmed the greater impacts of citrus compared with apple, mainly due to intensive practices associated with lower yield. It also produced novel references for peach and mango, for which no LCA studies could be found worldwide. Contrary to most LCA studies on perennial products, in the Agribalyse ${ }^{\circledR}$ methodology the whole perennial crop cycle was modeled, which represented important and systematic progress. Beyond these significant achievements, one should recall that in the Agribalyse ${ }^{\circledR}$ program the system boundaries were set at the farm gate, which represents a limitation to properly compare imported with local fruits. The first reason relates to the exclusion of the transport of imported fruits to their final market, which can represent significant impacts [35]. The second limitation is the non-inclusion at that stage of the quality requirements on fruits for export. From the total yield at the farm gate, only a fraction will have the required quality and will be allocated most of the impacts due to its higher economic value compared with the local quality fruits. Locally grown (French here) fruits also show different qualities but will all end up on the local market. Moreover, in Agribalyse ${ }^{\circledR}$ the functional unit used was the $\mathrm{kg}$ of raw fruit, while another important aspect for comparing fruits is the actual number of servings per $\mathrm{kg}$ fruit, also corresponding to their edible part $[12,15]$. Thus, the rules for a proper comparison of 
imported versus locally grown fruits need to be further formalized. At least the system boundaries should be extended beyond the farm gate to include transportation and conservation phases, fruit quality (including the edible part) and allocation issues between the different fruit qualities. Regarding the method used for estimating field emissions, the most consensual and up-to-date ones were chosen, which represented significant progress. However, the very generic emission factors used (such as IPCC or EMEP-CORINAIR ones) are not particularly valid for perennial crops under a semi-arid climate. This definitely represents an important margin of progress and perspective for research. Finally, although water deprivation can represent a key environmental problem for fruit production, this indicator could not be included in the Agribalyse ${ }^{\circledR}$ program and this should be completed in upcoming studies. Payen et al. [33] demonstrated in a full LCA study for imported versus locally grown tomato that impacts due to water use led to a reverse ranking of systems compared with the ranking obtained for climate change and other common impact categories.

\subsection{Data availability and design of representative systems}

All datasets were scored with an overall quality ranging from 2 to 3 corresponding to a "basic quality". One key difficulty of the Agribalyse ${ }^{\circledR}$ objectives was the design of representative systems in terms of technology, time and space. Significant discrepancies between situations were faced in terms of data quality and availability. Where statistical average systems could be calculated for some products, others such as fruits were mostly evaluated through expert-based scenarios (apple, peach, clementine) or small samples of farms (mango). Although expertise can be satisfactory for estimating most inputs and agronomic data, it is insufficient to capture the actual shares of pesticides used across a population. Knowing that certain active substances have high toxicity potential, not having this statistical representation constitutes a significant bias in the assessment of an average system. For French fruits, an additional effect has to be reported. Due to the French ECOPHYTO program aiming at drastically reducing pesticide use in France, most toxic substances have been banned since 2009 (the last year of the period covered by the Agribalyse ${ }^{\circledR}$ systems). This means that a lot of substances of pesticides used in our systems for apple and peach are no longer certified and used. Moreover, it is important to keep in mind that designing representative practices over a period of 25 years represents a contradiction in itself and a difficult challenge, especially for pesticide treatments which follow constantly changing rules. In addition, the recent understanding that the whole orchard life cycle should be included in LCA studies of perennials leads to a very data-intensiveprotocol that can be at the expense of the orchard variability exploration such as in our mango case study. Novel and less data-intensive strategies must be developed to allow the exploration of the variability of orchards within LCA studies for perennials, as discussed in Bessou et al. [34].

Finally, the fruit variety can play an important role in the eco-efficiency of the production system, due mostly to different yield potentials and sensitivity to different pests and diseases. Each fruit scenario was designed to represent the average situation in terms of variety, which is an important recommendation for fruit LCA studies.

\section{Conclusion}

The Agribalyse ${ }^{\circledR}$ program allowed the production of a vast and consensual LCI database for mostly French agricultural products including four fruits as presented in this paper. This was definitely an important step forward. For most impact categories, apple appeared to be the least impacting, followed by mango, peach and clementine. For each fruit cropping system, margins of improvement were identified and associated with agronomic recommendations. Generally speaking, the key aspects driving the eco-efficiency of fruit cropping systems at the farm gate are the yield, the fertilizer rates, the use of toxic substances, the water requirement associated with its local availability and the energy source for irrigation. Effort should be continued to improve the representativeness of average perennial cropping systems, develop the LCA beyond the farm gate, include water deprivation and improve the methods for estimating field emissions under perennial cropping conditions in the tropics and sub-tropics.

Acknowledgements. This work is part of the Agribalyse ${ }^{\circledR}$ program funded by ADEME. The authors warmly thank their partners in the field and all the experts that contributed to this study through their data, expertise and knowledge. Finally, the authors would like to thank the anonymous reviewers whose comments were very helpful in improving the quality of this paper.

\section{References}

[1] Cerutti A.K., Beccaro G.L., Bruun S., Bosco S., Donno D., Notarnicola B., Bounous G., Life cycle assessment application in the fruit sector: State of the art and recommendations for environmental declarations of fruit products, J. Clean. Prod. 73 (2014) 125-135.

[2] ISO, ISO 14040: Environmental management - Life cycle assessment principles and framework ISO, Geneva, Switzerland, 2006 .

[3] ISO, ISO 14044: Environmental management - Life cycle assessment requirements and guidelines, ISO, Geneva, Switzerland, 2006b.

[4] Sanjuán N., Úbeda L., Clemente G., Mulet A., Girona F., LCA of integrated orange production in the Comunidad Valenciana (Spain), Int. J. Agr. Res. Gov. Ecol. 4(2) (2005) 163-177.

[5] Beccali M., Cellura M., Iudicello M., Mistretta M., Resource consumption and environmental impacts of the agrofood sector: Life cycle assessment of Italian citrus-based products, Environ. Manage. 43 (2009) 707-724.

[6] Trydeman Knudsen M., Fonseca de Almeida G., Langer V., Santiago de Abreu L., Halberg N., Environmental assessment of organic juice imported to Denmark: a case study on oranges (Citrus sinensis) from Brazil, Org. Agr. 1 (2011) 167-185.

[7] Pergola M., D’Amico M., Celano G., Palese A.M., Scuderi A., Di Vita G., Papparlardo G., Inglese P., Sustainability evaluation of Sicily's lemon and orange production: An energy economic and environmental analysis, J. Environ. Manag. 128 (2013) 674-682. 
[8] Lo Giudice A., Mbohwa C., Clasadonte M.T., Ingrao C., Environmental assessment of the citrus fruit production in Sicily using LCA, Ital. J. Food Sci. 25 (2013) 202-212.

[9] Milà i Canals L., Burnip G.M., Cowell S.J., Evaluation of the environmental impacts of apple production using Life cycle assessment (LCA): Case study in New Zealand, Agr. Ecosyst. Environ. 114 (2006) 226-238.

[10] Mouron P.J.P., Nemecek T., Scholz R.W., Weber P., Management influence on environmental impacts in an apple production system on Swiss fruit farms: Combining life cycle assessment with statistical risk assessment, Agr. Ecosyst. Environ. 114 (2006) 311-322.

[11] Alaphilippe A., Simon S., Brun L., Hayer F., Gaillard G., Life cycle analysis reveals higher agroecological benefits of organic and low-input apple production, Agron. Sustain. Dev. 33 (2013) 581-592.

[12] Ingwersen W.W., Life cycle assessment of fresh pineapple from Costa-Rica, J. Clean. Prod. 35 (2012) 152-163.

[13] Bessou C., Basset-Mens C., Tran T., Benoist A., LCA applied to perennial cropping systems: a review focused on the farm stage, Int. J. LCA 18 (2013) 340-361.

[14] Cerutti A.K., Bruun S., Beccaro G.L., Bounous G., A review of studies applying environmental impact assessment methods on fruit production systems, J. Environ. Manag. 92 (2011) 2272286.

[15] Cerutti A.K., Beccaro G.L., Bruun S., Bosco S., Donno D., Notarnicola B., Bounous G., LCA applications in the fruit sector: State of the art and recommendations for environmental declarations of fruit products, J. Clean. Prod. 73 (2014) 125135.

[16] Koch P., Salou T., AGRIBALYSE ${ }^{\circledR}$ : Rapport méthodologique - Version 1.0. Ed ADEME, Angers, France, 2013, 401 p.

[17] Agreste, Surfaces en pomme et en pêche, On-line statistical data. Retrieved at: https://stats.agriculture.gouv.fr/disar/, 2008.

[18] EACCE, Bilan des statistiques d'exportation des agrumes, Retrieved at: http://web2.eacce.org.ma/, 2010

[19] Nemecek T., Kägi T., Life cycle inventories of Swiss and European agricultural production systems. Final report ecoinvent V2.0 No. 15a, Agroscope Reckenholz-Taenikon Research Station ART, Swiss Centre for Life Cycle Inventories, Zürich and Dübendorf, Switzerland, 2007, Retrieved from: www. econivent.ch.

[20] IPCC, IPCC Guidelines for National Greenhouse Gas Inventories, Prepared by the National Greenhouse Gas Inventories Programme, Eggleston H.S., Buendia L., Miwa K., Ngara T., Tanabe K. (eds.), IGES, Japan, 2006.

[21] EMEP/CORINAIR, Air pollutant emission inventory guidebook, Technical report No 11. Ed European Environment Agency (EEA), Copenhagen, Denmark, 2006.

[22] EMEP/EEA, Air pollutant emission inventory guidebook, Technical report No 9, European Environment Agency (EEA), Copenhagen, Denmark, 2009.

[23] Freiermuth R., Modell zur Berechnung der Schwermetallflüsse in der Landwirtschaftlichen Okobilanz, Agroscope FAL Reckenholz, Zürich, Switzerland, 2006, http://www.Agroscope. admin.ch/oekobilanzen/01194/

[24] SOGREAH, Bilan des flux de contaminants entrants sur les sols agricoles de France métropolitaine, Ed ADEME, Angers, France, 2007, 330 p.
[25] Goedkoop M., Heijungs R., Huijbregts M., De Schryver A., Struijs J., Van Zelm R., ReCiPe 2008, A life cycle impact assessment method which comprises harmonised category indicators at the midpoint and the endpoint level (version 1.08), Report I: Characterisation, 2013, $126 \mathrm{p}$.

[26] Hischier R., Weidema B., Althaus H.J., Bauer C., Doka G., Dones R., Frischknecht R., Hellweg S., Humbert S., Jungbluth N., Köllner T., Loerincik Y., Margni M., Nemecek T., Implementation of life cycle impact assessment methods, Ecoinvent report No. 3, v2.1, Swiss Centre for Life Cycle Inventories, Dübendorf, Switzerland, 2009.

[27] Guinée J.B., Gorrée M., Heijungs R., Huppes G., Kleijn R., de Koning A., van Oers L., Wegener Sleeswijk A., Suh S., Udo de Haes H.A., de Bruijn H., van Duin R., Huijbregts M.A.J., Life cycle assessment, An operational guide to the ISO standards, Centre of Environmental Science, Leiden University, Leiden, The Netherlands, 2002.

[28] European Commission, International Reference Life Cycle Data System (ILCD) Handbook - General guide for life cycle assessment, Joint Research Centre - Institute for Environment and Sustainability, Luxembourg, 2010.

[29] Namdari M., Kangarshahi A.A., Amiri N.A., Input-Output energy analysis of citrus production in Mazandaran province of Iran, Afr. J. Agric. Res. 6 (2011) 2558-2564.

[30] Frischknecht, R., Bollens, U., Bosshart, S., Ciot, M., Ciseri, L., Doka, G., Dones, R., Gantner, U., Hischier, R., Martin, A., Ökoinventare von Energiesystemen. Grundlagen für den ökologischen Vergleich von Energiesystemen und den Einbezug von Energiesystemen in Ökobilanzen für die Schweiz, Auflage No. 3, Gruppe Energie - Stoffe - Umwelt (ESU), Eidgenössische Technische Hochschule Zürich und Sektion Ganzheitliche Systemanalysen, Paul Scherrer Institut Villigen/Würenlingen, Schweiz, 1996.

[31] Dreyer, L.C., Niemann, A.L., Hauschild, M.Z., Comparison of three different LCIA methods: EDIP97, CML2001 and Ecoindicator 99, Int. J. LCA 8(4) (2003) 191-200.

[32] AIE (2014), Politiques énergétiques hors des pays de l'AIE : Maroc 2014, Éditions OCDE, Paris.

[33] Payen, S., Basset-Mens, C., Perret, S.R., LCA of local and imported tomato: an energy and water trade-off, J. Clean. Prod. 87 (2015) 139-148.

[34] Bessou C., Basset-Mens C., Latunussa C., Vélu A., Heitz H., Vannière, H., Caliman J.P., Partial modelling of the perennial crop cycle misleads LCA results in two contrasted case studies, Int. J. LCA (in press).

[35] Sim S., Barry M., Clift R., Cowell S.J., The relative importance of transport in determining an appropriate sustainability strategy for food sourcing, Int. J. LCA 12 (2007) 422-431

[36] Heijungs, R., Guinée, J.B., Huppes, G., Lankreijer, R.M., Udo de Haes, H.A., Wegener Sleeswijk, A., Ansems, A.M.M., Eggels, P.G., van Duin, R., Goede, H.P., Environmental life cycle assessments of products, guide and backgrounds, Centre of Environmental Science (CML), Leiden University, Leiden, The Netherlands, 1992. 